1. M.Phil.

Research Scholar, Department of Histopathology UHS, Lahore.

2. FCPS.

Department of Hematology, Aziz Fatimah Medical \& Dental College, Faisalabad.

3. M.Phil. Department of Histopathology PIMS, Islamabad.

4. M. Phil. (Research Scholar) Department of Histopathology PGMI, Lahore.

5. Ph.D.

Morbid Anatomy and Histopathology, UHS, Lahore.

6. Ph.D., FCPS, FCPP, FRCP, FRC (PATH)

Professor emeritus,

Consultant of Histopathology and Research analyst Chughtai Lab., Lahore.

7. M.Phil

Research Scholar,

Department of Histotechnology UHS, Lahore.

Correspondence Address:

Dr. Iram Asrar

Research Scholar,

Department of Histopathology

UHS, Lahore.

dr.iramarsalan@gmail.com

Article received on:

02/10/2019

Accepted for publication:

25/12/2019

\section{BREAST CARCINOMA: A CLINICOPATHOLOGICAL STUDY OF 90 CASES.}

\begin{abstract}
Iram Asrar ${ }^{1}$, M. Usman ${ }^{2}$, Saira Javeed ${ }^{3}$, Ammara Anwar $^{4}$, Nadia Naseem ${ }^{5}$, A.H Nagi ${ }^{6}$, Aysha Saeed ${ }^{7}$
ABSTRACT... Objective: To describe the clinicopathological features of breast carcinoma in the local population based on age, menopausal status, laterality, tumor site, tumor size, histological subtype, and histological grading of breast carcinoma. Study Design: Descriptive cross-sectional study. Setting: University of Health Sciences, Lahore. Period: 6 months (June 2017-Dec 2017). Material \& Methods: In this study, the clinicopathological profile of 90 female patients of breast carcinoma was evaluated from different tertiary care hospitals and U.H.S, Lahore. Histological diagnosis and histological grading was then carried out and were analyzed statistically through SPSS 21.0. Associations between the histological grade and other parameters were established using the Chi-square test. Results: The mean age of patients was $48.44 \pm 11.64$ with $33.3 \%$ of patients younger than 40 years of age and $58.9 \%$ of women were found pre-menopausal. The left breast was more involved $(65.6 \%)$ than the right side, upper outer quadrant of the breast was the commonest site $(64.4 \%)$, and the majority of the tumors (76\%) were more than $2 \mathrm{~cm}$ in size. All 90 cases were histologically diagnosed as invasive carcinoma of no special type (NST). Nottingham histological grade-Il was observed as the commonest grade (54.4\%) followed by grade- III (31.1\%). Histological grade was significantly associated with the tumor size $(p-v a l u e=0.000$, Chi-square value $=29.17$ ). Conclusions: Breast cancer is mostly reported in younger premenopausal women in our region. Delay in the diagnosis is most likely related to larger tumor sizes and moderate to poor histological grades.
\end{abstract}

Key words: $\quad$ Breast cancer, Invasive breast carcinoma of no special type (NST), Nottingham histological grade, Younger women.

Article Citation: Asrar I, Usman M, Javeed S, Anwar A, Naseem N, Nagi AH, Saeed A. Breast carcinoma: A clinicopathological study of 90 cases. Professional Med J 2020; 27(2):381-387. DOI: 10.29309/TPMJ/2020.27.2.4214

\section{INTRODUCTION}

Breast cancer represents the most commonly diagnosed malignant tumor in women globally. According to the statistics of the World Health Organization 2018, this cancer constitutes $24.2 \%$ of all cancers in females. It is the leading cause of cancer-related death in more than 100 countries. Breast cancer in Pakistan ranks highest in ten most frequently reported cancers in South-Asian countries in terms of both the incidence and the mortality. ${ }^{1}$ In Pakistan, it is the commonest malignancy in adult females $(44.56 \%)^{2}{ }^{2}$ According to the latest edition of the World Health Organization classification, epithelial breast tumors are recognized as microinvasive and invasive carcinomas. Invasive carcinomas are further classified into invasive carcinoma of no special type (IC-NST, 60-75\%) and the special invasive types (25\%). ${ }^{3}$ Invasive carcinoma of no special type (IC-NST) being the diagnosis of exclusion, fails to manifest adequate features for its classification to be asserted in one of the special types. The special types include lobular, tubular, cribriform, mucinous, carcinoma with medullary features, with apocrine and signet ring type, micropapillary, metaplastic carcinoma of no special type and with mesenchymal differentiation. ${ }^{4}$

Breast cancer has variegated morphological and molecular profiles with diverse clinical behavior and response to therapy based on geographical distribution. At present, the personalized management of breast cancer counts on stratification of risk based on patient's predilections, comorbidities, and well-recognized 
clinicopathologic factors. Some of these factors are the prognostic factors like age, ethnicity, tumor size, histological diagnosis and histological grade, the status of involved lymph nodes, lymphovascular invasion, and proliferation index. Histological grade and the Ki-67 index may also have predictive value. While other factors such as estrogen receptor status (ER), Progesterone receptor status (PR), and human epidermal growth factor receptor 2 (HER2) status, and genetic profiling possess both predictive and prognostic virtues. ${ }^{5,6}$ Nevertheless, classifying breast cancer via gene expression is of restricted advantage in routine clinical practice partly because of the costly and time-consuming nature of the tests.

Nottingham histological grading has been reported as one of the strongest predictors of the disease outcome in breast cancer patients. It is principally carried out for invasive adenocarcinomas. Nottingham grading system yields a simple and routinely applicable analysis. ${ }^{7}$ After the histological grade, the size of the primary tumor is also a strong prognostic entity being a part of the TNM staging system. ${ }^{8}$

The probability of survival (up to 5 years) in stage IV is $25 \%$ but, if detected at an early stage (I), it can be as high as 98.5\% (SEER review 1975-2016). ${ }^{9}$ The disease-free interval and overall-survival related to breast cancer have not been improving in developing countries like Pakistan. The mean age of breast cancer at the time of diagnosis in Pakistani women is also lower than various other countries. ${ }^{10}$ Therefore, there is a need to understand this heterogeneous malignancy in our region both clinically and pathologically to improve the standards of diagnosis and treatment specifically in younger women.

In this study, we focus on the clinicopathological parameters like age, menopausal status, laterality, tumor site in the breast, tumor size, and histological subtype with special emphasis on the histological grade in the local population of our region.

\section{MATERIAL \& METHODS}

This cross-sectional descriptive study was approved by the Advanced Studies and Research Board and also, by the ethical review committee of the University of Health Sciences, Lahore, Pakistan. This study was carried out in the department of Morbid Anatomy and Histopathology at the University of Health Sciences (UHS), Lahore. It was completed in a period of 6 months. Sample selection was made through a convenient sampling technique from U.H.S, Jinnah Hospital and Lahore General Hospital, Lahore. A total number of 90 formalinfixed, paraffin-embedded (FFPE) tissue blocks of female patients who underwent modified radical mastectomy with primary breast cancer were included. FFPE blocks were retrospectively selected through a thorough assessment of available surgical samples along with the medical record and pathological reports. Patients having chronic co-morbidities, immune disorders, chemotherapy, and/or autolyzed tissue samples were excluded from our study. To confirm the histological diagnosis and grading, sections from the blocks were then cut and processed for hematoxylin and eosin staining. Histological grading was carried out using Nottingham criteria ${ }^{7}$. The clinical and histopathological data were then entered and analyzed via SPSS 21.0. Frequencies and percentages were given for qualitative variables, whereas mean values, standard deviation, standard error, and the range was given for quantitative variables. The associations between the histological grades with other parameters were established by using the Pearson Chi-square test. A p-value of $\leq 0.05$ was considered statistically significant.

\section{RESULTS}

Patients included in this study ranged in age from 30 to 75 years. The mean age with standard deviation is given in Table-l. The majority of the patients were $30-40$ years of age (33.3\%) (Table-III). Menstrual history was obtained from the patient's medical records and $58.9 \%$ of females were found pre-menopausal in our study population (Table-III). Distribution regarding the laterality of the tumor is given in Figure-1. The site of these tumors was clinically and grossly 
evaluated in the breast. The majority of the tumors were found in the upper outer quadrant of the breast $(64.4 \%)$. The gross examination revealed that $44 / 90$ of these tumors were measured 2.1$5 \mathrm{~cm}$ in their greatest dimension. The mean size with the standard deviation was $4.74 \pm 2.96$. The histological diagnosis of all the cases was based on the latest WHO classification of breast tumors (2012). All the cases were diagnosed to be invasive carcinoma, of no special type (IC-
NST). Histological grade was assessed by the Nottingham grading system. The distribution of histological grades in terms of frequency and percentage is given in Table-II. Histological grade was associated with age, menstrual status, tumor site, and tumor size (Table-III). Statistically, a significant association was found between histological grade and the size of tumor with a chi-square value of 29.17 and a p-value of 0.000 $(<0.05)$.

\begin{tabular}{|l|c|c|c|c|c|c|c|}
\hline \multicolumn{1}{|c|}{ Characteristics } & N & Range & Min. & Max. & Mean & SE & SD \\
\hline Age & 90 & 45.00 & 30.00 & 75.00 & 48.44 & 1.227 & 11.64 \\
\hline Tumor size (cm) & 90 & 18.80 & 1.50 & 20.30 & 4.74 & 0.312 & 2.96 \\
\hline Nottingham Histological score & 90 & 4.00 & 4.00 & 8.00 & 6.78 & 0.117 & 1.11 \\
\hline
\end{tabular}

Table-I. Descriptive statistics of clinicopathological characteristics.

(Min. = Minimum, Max. = Maximum, SE = Standard Error, SD= Standard Deviation)

\begin{tabular}{|c|c|c|}
\hline Grade & Frequency & Percent \\
\hline G-I & 13 & 14.4 \\
\hline G-II & 49 & 54.4 \\
\hline G-III & 28 & 31.1 \\
\hline Total & 90 & 100.0 \\
\hline
\end{tabular}

Table-II. Distribution regarding histological grade.

\begin{tabular}{|c|c|c|c|c|c|c|}
\hline \multirow{2}{*}{\multicolumn{2}{|c|}{ Clinicopathological parameters }} & \multicolumn{3}{|c|}{ Histological Grade Count and percentage } & \multirow{3}{*}{$\begin{array}{c}\begin{array}{c}\text { Total Count and } \\
\text { Percentage }\end{array} \\
30 \\
\end{array}$} & \multirow{2}{*}{ P-Value } \\
\hline & & G-I & G-II & G-III & & \\
\hline \multirow{8}{*}{ Age groups } & \multirow{2}{*}{$\leq 40$} & 7 & 15 & 8 & & \multirow{8}{*}{0.773} \\
\hline & & $53.80 \%$ & $30.60 \%$ & $28.60 \%$ & $33.30 \%$ & \\
\hline & \multirow{2}{*}{$41-50$} & 3 & 13 & 7 & 23 & \\
\hline & & $23.10 \%$ & $26.50 \%$ & $25.00 \%$ & $25.60 \%$ & \\
\hline & \multirow{2}{*}{$51-60$} & 2 & 14 & 9 & 25 & \\
\hline & & $15.40 \%$ & $28.60 \%$ & $32.10 \%$ & $27.80 \%$ & \\
\hline & \multirow{2}{*}{$61+$} & 1 & 7 & 4 & 12 & \\
\hline & & $7.70 \%$ & $14.30 \%$ & $14.30 \%$ & $13.30 \%$ & \\
\hline \multirow{4}{*}{$\begin{array}{l}\text { Menstrual } \\
\text { status }\end{array}$} & \multirow{2}{*}{$\begin{array}{c}\text { Post- } \\
\text { menopausal }\end{array}$} & 3 & 20 & 14 & 37 & \multirow{4}{*}{0.264} \\
\hline & & $23.10 \%$ & $40.80 \%$ & $50.00 \%$ & $41.10 \%$ & \\
\hline & \multirow{2}{*}{$\begin{array}{c}\text { Pre- } \\
\text { menopausal }\end{array}$} & 10 & 29 & 14 & 53 & \\
\hline & & $76.90 \%$ & $59.20 \%$ & $50.00 \%$ & $58.90 \%$ & \\
\hline \multirow{6}{*}{ Tumor site } & \multirow{2}{*}{ Central } & 3 & 11 & 11 & 25 & \multirow{6}{*}{0.407} \\
\hline & & $23.10 \%$ & $22.40 \%$ & $39.30 \%$ & $27.80 \%$ & \\
\hline & \multirow{2}{*}{$\begin{array}{l}\text { Lower outer } \\
\text { quadrant }\end{array}$} & 2 & 3 & 2 & 7 & \\
\hline & & $15.40 \%$ & $6.10 \%$ & $7.10 \%$ & $7.80 \%$ & \\
\hline & \multirow{2}{*}{$\begin{array}{l}\text { Upper outer } \\
\text { quadrant }\end{array}$} & 8 & 35 & 15 & 58 & \\
\hline & & $61.50 \%$ & $71.40 \%$ & $53.60 \%$ & $64.40 \%$ & \\
\hline \multirow{6}{*}{ Tumor size } & \multirow{2}{*}{$\leq 2.0$} & 8 & 6 & 0 & 14 & \multirow{6}{*}{0.000} \\
\hline & & $61.50 \%$ & $12.20 \%$ & $0.00 \%$ & $15.60 \%$ & \\
\hline & \multirow{2}{*}{$2.1-5.0$} & 4 & 27 & 13 & 44 & \\
\hline & & $30.80 \%$ & $55.10 \%$ & $46.40 \%$ & $48.90 \%$ & \\
\hline & \multirow{2}{*}{$5.1+$} & 1 & 16 & 15 & 32 & \\
\hline & & $7.70 \%$ & $32.70 \%$ & $53.60 \%$ & $35.60 \%$ & \\
\hline \multirow{2}{*}{ Grade Total } & Count & 13 & 49 & 28 & 90 & \\
\hline & Percentage & $14.4 \%$ & $54.4 \%$ & $31.1 \%$ & $100 \%$ & \\
\hline
\end{tabular}

Table-III: Distribution and association of clinicopathological parameters with the histological grades $(n=90)$. 


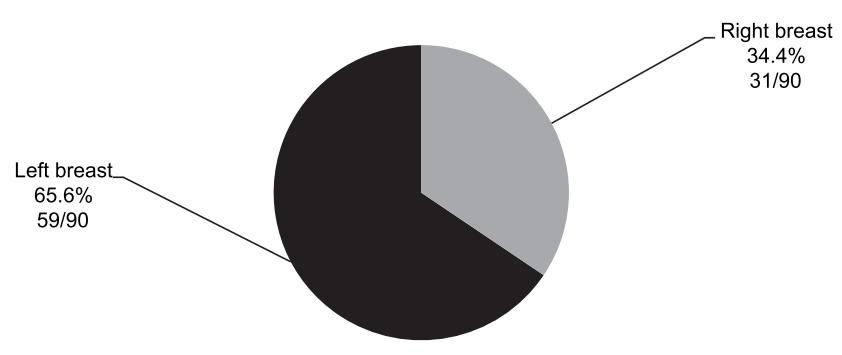

Figure-1: Distribution regarding laterality.

\section{DISCUSSION}

According to the statistics of SEER, the estimated cases of breast cancer in females in 2019 will be 268,600 and it will result in 41,760 estimated deaths. ${ }^{11}$ The incidence of breast cancer is variable worldwide but Pakistan has the highest age-standardized incidence and mortality rates among the Asian countries. ${ }^{12,1}$ Among various risk factors of breast cancer, advancing age is the cardinal one. It is mostly diagnosed in females around menopause. About 40 to $60 \%$ of patients who suffer from breast cancer in Pakistan are reported to present at a relatively advanced Stage III or IV, as compared to the western population. ${ }^{12}$ Low socioeconomic and educational status, environmental pollution, lack of awareness, delay in diagnosis, limited access to minimum expected treatment, shortage of oncology centers with technical staff, and lack of support from higher authorities have created an extremely alarming situation in Pakistan. ${ }^{12}$ Some ethnicities are reported to have a greater risk of particular subtypes of breast cancer than other racial groups. There are no enthralling facts and figures to apprehend the precise magnitude of the problem in various ethnicities in different age groups. ${ }^{13}$

The incidence of breast cancer has steadily raised among younger Pakistani women in the last decade with a shift in mean age from 50 to 45.75 years. ${ }^{14}$ This higher percentage of younger women having breast cancer in our study was consistent with various other studies like 39.17 $\pm 6.019 .{ }^{15}$ In other Pakistani studies including the data collected from the largest cancer center, Shaukat Khanum memorial cancer hospital and research center-Lahore, the observed mean age was 40-49 years. $^{16,17,10}$ Our findings regarding age groups were contrary to the reported data of Surveillance, Epidemiology and End Results (SEER, 1975-2016) which reveals the highest rate of incidence between 70-79 years. ${ }^{9}$ Early-onset breast carcinomas are reported to be consistent with bad prognosis indicating genetic instability and aggressive biological properties. ${ }^{18}$ This implies separate screening with different local and systemic therapeutic measures to be established in younger vs older women.

Our results concerning menopausal status correspond to the higher percentage of premenopausal women in other studies carried out in Pakistan like $57.3 \%{ }^{10}$ and $50.5 \% .{ }^{17}$ A study conducted by Tamimi et al. in 2016 studied that the majority of the U.S registered nurses with breast cancer $(44.1 \%)$ were in the age group between

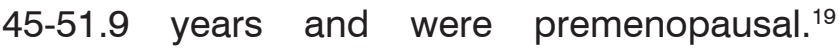
It is contrary to the higher percentage of postmenopausal women (52.3\%) in a study on Japanese women ${ }^{20}$ and $65.5 \%$ in the Chinese population. ${ }^{21}$ Family history and genetic makeup have been associated with premenopausal breast cancer whereas, diets high in fat content, obesity, and sedentary lifestyle are linked to postmenopausal breast cancer. ${ }^{22}$ This gives us an insight that a substantial reduction of breast cancer is possible in one-third of postmenopausal women with the prevention of modifiable risk factors. Public awareness has a special role in this regard.

The site and laterality of breast cancer have been previously studied to establish them as independent prognostic factors. Breast cancer in the upper outer quadrant is considered to have a better outcome whereas, the central location of the tumor is linked to a larger size as it is diagnosed later and therefore results in a relatively bad prognosis. ${ }^{23}, 24$ Our findings regarding the laterality of breast cancer are similar to the published data. ${ }^{16}$ However, it was found in a study in 2018 that tumors in the lower outer quadrant had a better prognosis contradicting the usual upper outer quadrant location. ${ }^{24}$

The size of the primary tumor has been studied 
in association with prognosis. The larger the size of the tumor, the greater is the chance for nodal and distant metastasis, decreased 5-year survival rates and hence, a bad prognosis. ${ }^{25}$ Regarding tumor size, a recent Pakistani study conducted in 2017 by Naqvi et al. ${ }^{16}$ revealed that $88.1 \%$ of tumors were more than $2 \mathrm{~cm}$ in size. Another study conducted in Pakistan in $2015^{17}$ established that increasing tumor size from less than $2 \mathrm{~cm}$ to more than $5 \mathrm{~cm}$, increases the chance of lymph node involvement from $37 \%$ to $90 \%$. Therefore, the large size of tumor is linked to local and distant metastasis and poor outcome. Our results are contrary to several western studies, where a $100 \% 5$-year-survival is seen with a routine size of $\leq 2 \mathrm{~cm}$. ${ }^{1}$ We observed tumors as large as 20 $\mathrm{cm}$ in the greatest dimension. This is due to lack of effective screening and delayed diagnosis in our population. This finding is less commonly observed in western countries.

Several studies validate the major role of tumor grade and histological subtype in the prognosis of breast cancer patients. ${ }^{7}$ In our study, it was observed that the majority of the tumors were moderately to poorly differentiated (Table-II). Our findings were much similar to other studies conducted in Pakistan. ${ }^{10,16}$ When histological grade was related to other parameters, then a significant association was established between histological grade and the size of the tumor. Our results showed that the degree of differentiation in tumor decreased with an increase in the size of tumor (Table-III). This was in consonance to the published literature. ${ }^{26}$

\section{CONCLUSION}

In light of the results of this study, it may be concluded that most cases of breast cancer are reported in younger women in our region as compared to the western population. The left breast is most commonly affected with upper outer quadrant being the commonest site. Histologically, invasive carcinoma, of no special type is the commonest type of breast cancer. Larger tumor sizes $\left(T_{2}\right.$ and $T_{3}$ category) and moderate to poor histological grades (Grade-II and Grade-III) are common presentations. Delay in diagnosis and aggressive behavior of tumors at a younger age can be attributed to these findings. Considering the rising trends in the incidence and mortality of breast cancer, this study emphasizes screening and early diagnosis of breast cancer especially in younger women of our population.

\section{Recommendations:}

Prospective cohort studies are recommended to further understand the heterogeneous behavior of breast cancer in our region concerning survival.

\section{Conflict of interest:}

This study has no conflict of interest to declare by any author.

\section{Copyright $(25$ Dec, 2019.}

\section{REFERENCES}

1. Ferlay J, Colombet M, Soerjomataram I, Mathers C, Parkin DM, Piñeros M, Znaor A, Bray F. Estimating the global cancer incidence and mortality in 2018: GLOBOCAN sources and methods. International journal of cancer. 2019 Apr 15; 144(8):1941-53.

2. Punjab Cancer Registry. (2016). Punjab cancer registry report 2016. [Online]. Available at: (http:// punjabcancerregistry.org.pk/reports/PCR_2016.pdf) [Accessed 6 $6^{\text {th }}$ April, 2018].

3. Lakhani SR, editor. WHO Classification of Tumours of the Breast. International Agency for Research on Cancer; 2012.

4. Sinn HP, Kreipe H. A brief overview of the WHO classification of breast tumors. Breast care. 2013; 8(2):149-54.

5. Cianfrocca M, Goldstein LJ. Prognostic and predictive factors in early-stage breast cancer. The oncologist. 2004 Nov 1; 9(6):606-16.

6. Weigel MT, Dowsett M. Current and emerging biomarkers in breast cancer: prognosis and prediction. Endocrine-related cancer. 2010 Dec1; 17(4):R245-62.

7. Rakha, E.A., and Ellis, I.O., 2017. Grading of Invasive Carcinoma. In Breast Pathology (pp. 87-95). Springer, Cham

8. Giuliano AE, Connolly JL, Edge SB, Mittendorf EA, Rugo HS, Solin LJ, Weaver DL, Winchester DJ, Hortobagyi GN. Breast cancer-major changes in the American Joint Committee on Cancer eighth edition cancer staging manual. CA: A cancer journal for clinicians. 2017 Jul 8; 67(4):290-303. 
9. Howlader N, Noone AM, Krapcho M, Miller D, Brest A, Yu M, Ruhl J, Tatalovich Z, Mariotto A, Lewis DR, Chen HS, Feuer EJ, Cronin KA (eds). SEER Cancer Statistics Review, 1975-2016, National Cancer Institute. Bethesda, MD, https://seer.cancer.gov/csr/1975_2016/, based on November 2018 SEER data submission, posted to the SEER web site, April 2019

10. Badar F, Mahmood S, Faraz R, Yousaf A, Quader AU, Asif $\mathrm{H}$. Epidemiology of breast cancer at the Shaukat Khanum memorial cancer hospital and research center, Lahore, Pakistan. J Coll Physicians Surg Pak. 2015 Oct 1;25(10):738-42.

11. Surveillance epidemiology and end results: National Cancer Institute [Internet]. 2019[cited 2019 Sep 21]. Available from: http://seer.cancer.gov/

12. Basra MA, Saher M, Athar MM, Raza MH. Breast cancer in Pakistan a critical appraisal of the situation regarding female health and where the nation stands. Asian Pacific Journal of Cancer Prevention. 2016 Jul $1 ; 17(7): 3035-41$.

13. Kurian AW, Fish K, Shema SJ, Clarke CA. Lifetime risks of specific breast cancer subtypes among women in four racial/ethnic groups. Breast Cancer Research. 2010 Dec 1;12(6):R99.

14. Khaliq SA, Naqvi SB, Fatima A. Retrospective study of cancer types in different ethnic groups and genders at Karachi. Springerplus. 2013 Dec 1; 2(1):118.

15. Malik AM, Pathan R, Shaikh NA, Qureshi JN, Talpur KA. Pattern of presentation and management of $\mathbf{C a}$ breast in developing countries. There is a lot to do. JPMA. 2010 Sep 15;60(718).

16. Naqvi SR, Farhat K, Naqvi SS, Rashid MM, Sheikh IA, Ali M. Breast cancer: clinical and histopathological features at combined military hospital Rawalpindi. Pakistan Armed Forces Medical Journal. 2017 Aug 30; $67(4): 540-44$.

17. Mahmood H, Faheem M, Mahmood S, Sadiq M, Irfan J. Impact of age, tumor size, lymph node metastasis, stage, receptor status and menopausal status on overall survival of breast cancer patients in Pakistan. Asian Pac J Cancer Prev. 2015; 16(3):1019-24.
18. Anastasiadi Z, Lianos GD, Ignatiadou E, Harissis HV, Mitsis M. Breast cancer in young women: an overview. Updates in surgery. 2017 Sep 1; 69(3):313-7.

19. Tamimi RM, Spiegelman D, Smith-Warner SA, Wang M, Pazaris M, Willett WC, Eliassen AH, Hunter DJ. Population attributable risk of modifiable and nonmodifiable breast cancer risk factors in postmenopausal breast cancer. American journal of epidemiology. 2016 Dec 14; 184(12):884-93.

20. Islam T, Matsuo $\mathrm{K}$, Ito $\mathrm{H}$, Hosono $\mathrm{S}$, Watanabe $\mathrm{M}$, Iwata $H$, Tajima K, Tanaka $H$. Reproductive and hormonal risk factors for luminal, HER2-overexpressing, and triple-negative breast cancer in Japanese women. Annals of oncology. 2012 Feb 10; 23(9):2435-41.

21. Devi CB, Tang TS, Corbex M. Incidence and risk factors for breast cancer subtypes in three distinct South-East Asian ethnic groups: Chinese, Malay and natives of Sarawak, Malaysia. International journal of cancer. 2012 Dec 15; 131(12):2869-77.

22. Assi HA, Khoury KE, Dbouk H, Khalil LE, Mouhieddine $\mathrm{TH}$, El Saghir NS. Epidemiology and prognosis of breast cancer in young women. Journal of thoracic disease. 2013 Jun; 5(Suppl 1):S2.

23. Rummel S, Hueman MT, Costantino $\mathrm{N}$, Shriver CD, Ellsworth RE. Tumour location within the breast: Does tumour site have prognostic ability? Ecancermedicalscience. 2015; 9.

24. Siotos C, McColl M, Psoter K, Gilmore RC, Sebai ME, Broderick KP, Jacobs LK, Irwin S, Rosson GD, Habibi M. Tumor Site and Breast Cancer Prognosis. Clinical breast cancer. 2018 Oct 1; 18(5):e1045-52.

25. Jensen MB, Nielsen TO, Knoop AS, Laenkholm AV, Balslev E, Ejlertsen $B$. Mortality and recurrence rates among systemically untreated high risk breast cancer patients included in the DBCG 77 trials. Acta Oncologica. 2018 Jan 2; 57(1):135-40.

26. Zheng K, Tan JX, Li F, Li HY, Zeng XH, Ma BL, Ou JH, $\mathrm{Li} H$, Yang SS, Jiang AM, Ni Q. Clinicopathologic Factors Related to the Histological Tumor Grade of Breast Cancer in Western China: An Epidemiological Multicenter Study of $\mathbf{8 6 1 9}$ Female Patients. Translational oncology. 2018 Aug 1; 11(4):1023-33. 


\section{AUTHORSHIP AND CONTRIBUTION DECLARATION}

\begin{tabular}{|c|c|c|c|}
\hline Sr. \# & Author(s) Full Name & Contribution to the paper & Author(s) Signature \\
\hline 1 & Iram Asrar & $\begin{array}{l}\text { Principal and Corresponding } \\
\text { Author, Conception, Data } \\
\text { collection, Synthesis and planning } \\
\text { of the research interpretation, } \\
\text { Analysis and discussion. }\end{array}$ & \\
\hline 3 & Saira Javeed & Data collection. & \\
\hline 4 & Ammara Anwar & Data collection. & \\
\hline $\begin{array}{l}5 \\
6\end{array}$ & $\begin{array}{l}\text { Nadia Naseem } \\
\text { A.H Nagi }\end{array}$ & $\begin{array}{l}\text { Conception and planning of the } \\
\text { research and reviewer. } \\
\text { Supervisor and Reviewer. }\end{array}$ & \\
\hline 7 & Aysha Saeed & $\begin{array}{l}\text { Active participation in } \\
\text { methodology. }\end{array}$ & \\
\hline
\end{tabular}

